\title{
Optimizing Wind Power for Energy Efficient Building Design in Tropical Hot-humid Climate of Malaysia
}

\author{
Abdul Malek Abdul Rahman (Corresponding author) \\ School of Housing, Building and Planning, Universiti Sains Malaysia \\ 11800 Minden, Penang, Malaysia \\ Tel: 604-653-2-810 E-mail: malik@usm.my \\ Hirda Lailani Khalid \\ School of Housing, Building and Planning, Universiti Sains Malaysia \\ 11800 Minden, Penang, Malaysia \\ E-mail: hlk09_hbp052@student.usm.my \\ Yusri Yusup \\ School of Industrial Technology, Universiti Sains Malaysia \\ 11800 Minden, Penang, Malaysia \\ Tel: 604-653-3888 Ext: 5201 / 4300 E-mail: yusriy@usm.my
}

Received: November 23, 2010

Accepted: December 20, 2010

doi:10.5539/jsd.v4n2p217

\begin{abstract}
Being a member of the Kyoto Protocol, Malaysia is obligated to initiate programs to reduce global warming according to its own availability of indigenous resources. It is to explore and optimize whatever possibilities that can be contributed from its domestic region. Several initiatives have been taken to capitalize on what Malaysia is abundant with and one of its renewable resources is solar energy. It has been reported that to rely on wind energy would be futile because of the characteristics of wind in tropical climates are unpredictable, erratic and multi-directions. Several design strategies have been attempted to encourage air movement into Malaysian buildings but because of the nature of its climate where the average diurnal range is low, indoor air movement has to be induced by electric fan or air-conditioning. However, thus consumes a lot of electricity every month. This is clearly not good to reduce global warming. This paper explores of what extent can wind or air movement be contribute and be better utilized as an alternative energy to achieve Malaysia's initiative to meet the Kyoto Protocol requirements.
\end{abstract}

Keywords: Tropical climate, Wind energy, Alternative energy, Sun energy

\section{Introduction}

The tropical hot and humid climate of Malaysia necessitates the use of all kinds of mechanical systems to cool the surroundings. To feel comfortable one has to be under a shade and experience ample air movement concurrently (Abdul Malek, 1994). Discomfort would set in when one element is missing. When being exposed under the tropical sun, one would experience the stifling heat unless the wind is of ample velocity (normally $>$ $2.0 \mathrm{~m} / \mathrm{s}$ ) to rid off the radiant heat. When under a shade, an air velocity of $1.0 \mathrm{~m} / \mathrm{s}$ is sufficient. At night time, the surrounding areas needed ample wind to get rid off the high relative humidity. Otherwise, the high humidity in the air gives the feeling of stickiness on the human skin and this is another source of discomfort. It is unfortunate that the tropical climate in Malaysia is described as hot and humid and has no reference to wind. This means that the much desired wind in Malaysia for natural thermal comfort cannot be depended upon because of its characteristic behavior i.e., unpredictable, multidirectional and erratic however when there is wind the velocity may not be of the required speed for comfort. As a result, air conditioning, fan and misting fountain were used. These then adds to running cost especially where air-conditioning takes up nearly $70 \%$ of the electricity bill in most hotels (Buttgen, 2002; Personal Communication).

Generally, Western tourists would flock to Malaysia to bask under the Malaysian sun of the beach and this is a typical and habitual behavior. So for the same reason as most other hotels in other parts of the world, most hotel locations would be along the fringes of attractive beaches. This is one of the indications that sun energy is abundant in Malaysia and a campaign known as 'Suria 1000' which has been running for five years, beginning from 2005 is about to end where a final report would assess the success of the campaign in getting Malaysians to adopt solar electricity into their homes. 
An increase in the cost of electricity tariffs up to $12 \%$ in May 2006 for commercial activities, including the hotel industry (News Straits Times, 2006), the increase in petrol prices and another hike in electricity tariff in early July 2008, have compelled almost those in business activities to brace themselves to be frugal. For example, a General Manager of a particular hotel in Penang resorted to switching off air conditioning for one hour at the administrative section in order to save energy. This is not the right move as productivity of the staff would be affected. Thus, steps should be taken towards energy efficiency in all activities.

\section{Natural Wind- Bioclimatic Design}

The habitual behavior of most Malaysians would be to open up windows as a gesture to welcome the day. Customarily when windows at home are closed during daytime would symbolize that one is not at home. As the weather gets too hot, closed windows would mean that the interior is being air-conditioned. Many years ago wind was depended upon to give a cooling effect but as population grew and buildable land became scarce, wind is no more a factor to give comfort cooling since the air outside is warmed by the sun's heat, an average temperature of at least $33^{\circ} \mathrm{C}$ and gradually increasing due to global warming. Even though, it is only when the air mass is warmed, there exists wind. This is due to the thermo-syphonic effect (Figure 1) which normally occurs in the late morning and a greater part of the afternoon

If this was the case as normally observed and reported, then it is caused by the heat island designed by man himself that causes the discomfort from the warm air. It has been a common practice in the Malaysian built environment to readily hard-landscaped the land cleared for physical development for the sake of aesthetics and easier maintenance. But later this was found to be the cause of heat islands that aggravated the already warm tropical climate of Malaysia.

Any building interiors at ground level opened up to a courtyard or surface with hard landscape that would receive warm air whenever wind is blowing, unless the surface is covered with turfs and trees as green measures. Most of the physical development of Malaysian built environment was unaware of this effect and aesthetics takes priority over comfort because comfort can be obtained by air-conditioning. Such development is not friendly to the tropical environment so much so that the Green Building Index of Malaysia has factored that any effort to prevent heat islands can gain points for rating physical development (Green Building Index, 2009). In this document, abiding the Sustainable Site Planning \& Management code SM12: Greenery \& Roof; A Hardscape \& Greenery Application condition would gain one point, states;

Provide any combination of the following strategies for $50 \%$ of the site hardscape (including sidewalks, courtyards, plazas and parking lots):

1) Shade (within 5 years of occupancy);

2) Paving materials with a Solar Reflectance Index (SRI) of at least 29;

3) Open grid pavement system;

The idea was to cool the surrounding atmosphere with soft landscaping and cool air movement easily created whenever there is wind, thus able to cool the building interiors and energy used for air-conditioning which can be minimized. Less dependence on air-conditioning means savings in electrical consumption thereby less demand on the burning of the fossil fuels. In the long run the worsening of the global warming can be curtailed.

\subsection{Land and Sea Breeze and Prevailing Wind of Hill Slopes}

Only two natural phenomena (Abdul Malek, 2004) can be identified to provide ample air velocities which can have an influence in the design of buildings. They are normally experienced at locations (i) by the beach geographically termed as land and sea breezes and (ii) the prevailing winds of the hill slopes. If this is the case then building designers should incorporate this endowment into the design of building located between the land and sea or large water bodies. The hypothesis that temperature discomfort can be alleviated by higher air velocity was verified by Azusa (2009). The objective was to determine whether the average natural air velocity can reduce thermal discomfort at hotel lobbies so as to depend less on air- conditioning.

In a field investigation done at a Masters level study, the passive element is to make full use of the wind both from the land and sea breezes phenomenon and the prevailing wind from the hill slopes. Two locations of hotel building were identified to represent the situations, namely, one located by the sea and the other perched on top of a small hill. The study limits itself to the hotel lobby as this would be ideal for natural cross ventilation.

Two hotel lobbies were chosen for the investigation because most hotel lobbies in Malaysia have high ceilings with big air volumes. In city hotels air-conditioning is resorted to for thermal comfort because it would not be suitable to have an open design concept due to factors such as noise pollution, dusts and thermal discomfort from warm air due to outdoor heat islands. Hill hotels and beach hotels are the two building types that can be investigated to acclaim energy efficiency in lobby designs by capitalizing on natural ventilation. Mountain locations do not pose any problem with heat thermal discomfort. The cooler average temperature is usually most welcomed by the locals. So a hotel on a hill slope in this investigation was identified not for comparison with all hill hotels but taken as an exploratory investigation to verify the hypothesis that hill slopes locations can make full use of the air velocity into designing of buildings. Several beach hotels are also located by the seaside but only one particular hotel was investigated because of the same scale and size of building mass with the other two 
hotels adjacent to it on the left and right. The adjacent hotel on the right side of the experimented hotel has its lobby totally enclosed and air-conditioned throughout, an energy inefficient design. Unlike the hotel under investigation where the lobby has no air-conditioning but depended solely on the natural behavior of the outdoor climate. This is an ideal building to be referred to as it took consideration of the land and sea breeze thermal behavior incorporated in its design.

The land and sea breeze phenomenon is termed because of the different surface masses meeting at a junction. Land is denser than the sea and therefore during daytime it is heated more rapidly than the sea. Heated land will create a zone of low pressure as the hot air rises to the atmosphere above. This low pressure is then filled up with relatively cooler air from above the sea mass by the process known as thermo-siphon and is referred to as the sea breeze since the breeze comes from the sea. At night the reverse is known as the land breeze because again land being the denser surface would release heat absorbed during the day rapidly than the sea thus becomes cooler than the sea (Figure 2a).

The hill slope prevailing wind phenomenon is termed because of the thermal properties of air mass being warmed or cooled. Warm air mass would rise up due to its low density, and cool air, usually occurring in the evenings and into the night would be heavier than warm air would therefore slide along the slopes of the hill to the bottom of the valley. This process creates air movement that can be tapped for use in buildings built along ridges of hills or along hill slopes (Figure $2 b$ ).

As a conclusion from this investigation, the hypothesis is the capitalization of natural ventilation helps to reduce the cost of monthly bills for cooling the hotel interiors to provide comfort for the hotel guests and local occupants. The two experiments carried out showed that by identifying and understanding the natural behavior of wind in tropical Malaysia, the hotel industry or any buildings to be erected on plots between the land and sea and/or hill slopes can employ the idea of using predictable wind conditions to reduce the business overheads. In Malaysia only two locations were identified as having more predictable wind conditions than any other parts of Malaysia. Though it cannot be totally relied upon for $100 \%$ of the time but identifying where such locations are, would help to influence the designs for new buildings and as for existing ones, renovations can be done to retrofit the idea. Land and sea breeze and prevailing winds of hill slopes are the two locations that provide consistently predictable wind conditions. Other parts of Malaysia as such the country lowlands interior and urban settings would describe the wind condition as unpredictable, multi-directional with erratic wind speeds and therefore unreliable to be used for building design purposes. One way is to extract the hot air from building interiors as quickly as possible and normally where the hot air rises, any solutions would be effective such as the existing turbine ventilator and jack roof.

The Standard Effective Temperature (SET) is a temperature indicator as it takes the considerations of other climatic elements and not just relying on the air temperature alone.

1) Both the investigations showed that the SET are below the air temperature averaging $1^{\circ} \mathrm{C}-1.5^{\circ} \mathrm{C}$. When it comes to thermal comfort a $1^{\circ} \mathrm{C}$ drop would make a significant difference in comfort and also in the reduction of energy consumption. This saves a lot of energy monthly bills.

2) There is somehow a general mirror image between the SET and the air velocity, especially from $12.00 \mathrm{pm}$ to $6.00 \mathrm{pm}$ for the beach hotel and from $8.00 \mathrm{am}$ to $3.00 \mathrm{pm}$ for the hill hotel. This means that when there is wind the temperature of a particular space will drop (Table 1). But the indoor climatic behavior differs during the evening. Without the presence of wind the temperature still drops simply because there is no sun to heat any air mass.

3) Both the SET falls within the Malaysian Thermal Comfort zone, i.e., within $24^{0} \mathrm{C}$ to $28^{0} \mathrm{C}$ (Abdul Shukor, 1993). The SET of the beach hotel seemed to be on the higher side within the comfort zone and for the hill hotel was more towards the mid-section of the comfort zone. Since the period of measurement was taken at different weeks it is highly likely that the week taken for the beach hotel was experiencing higher air temperatures. Nevertheless it is important to note that both are within the stipulated comfort zone and that air velocity was the determinant factor to bring down warm temperatures.

The conclusion of the above investigations showed the hypothesis has been verified. Architects and other building professionals are to take heed that these proven findings specifically at these two geographical locations and phenomena, wind can influence the building designs. These two hotels under investigation were wise enough to design their lobbies capitalizing on natural ventilation. Air-conditioned hotel lobbies normally would set their temperature indoors at $22^{\circ} \mathrm{C}$. The designed outside air temperature for air-conditioners was set at $33^{\circ} \mathrm{C}$ by mechanical engineers of air-conditioners. The lower the temperature set at the air-conditioner unit the more energy is consumed to extract the moisture from the outside air before releasing the dry cold air into the interiors (Ismail, 2000). Therefore the best practice is to reduce the gap between the outdoor temperature and the indoor temperature. Twenty-two degrees centigrade is far too low and the difference between outside air temperature and indoor temperature is too wide. 


\subsection{Altitude}

The bioclimatic design of buildings does not only influence building floors at low level but can also influence the façade treatment of high rise buildings. The land and sea breeze and the prevailing of hill slopes phenomena are usually associated with conditions of the rural setting but as for the urban setting, the approach has to be different. So far there has no research being done as to the building height where wind can be predictable to be invited into the building interiors to reduce dependence on air-conditioning but on the principle that the higher the altitude the faster the wind (Figure 3a), it is sure enough to influence the treatment of the high rise building façade to accommodate this principle. For instance, the first few floors starting from the ground floor can be designed to resist warm air generated from heat islands, thus a closed system, and the higher floors may be of a different design treatment as an open system (Figure 3b), a variation from Architect Ken Yeang's skyscraper designs where every floor has a totally different layout (Richards, 2001).

At times when there is equilibrium in temperature there may not be any wind at all (calm situation). Discomfort would then sets in. When this happens it is highly recommended that electrical fans be installed to achieve comfort level thereby obliterating the dependency on air-conditioning. Between fans and air-conditioning, fans are much more inexpensive to operate. Reduction in energy consumption means overheads are less and thereby pose more competitively in the hotel industry.

\section{Exhaust Air}

The above section discussed on the presence of predictable natural wind in typical locations may influence the physical design of buildings. It is imperative to have the skill in identifying situations where there is predictable wind otherwise physical development may be expensive to be retrofitted later on. The majority of existing Malaysian buildings are air-conditioned. Those with split units would have the compressors located either outside on the ground level or fixed with steel braces on external walls up above. These compressors use conventional energy for its operation and contribution to the depletion of fossil fuel and at the same time releases hot air to the immediate surrounding space, thus aggravating the already warm climate. The hypothesis is that the return air from air conditioning system can ensure the air velocity needed to generate electricity thus obviates the dependence on the unreliable natural wind speeds in Malaysia. This then becomes another alternative energy source.

Though small-scaled and stand alone but multiples of it would be an effective alternative for generating electricity where conventional generation is not practical (Ahmed et al., 2009). Moreover, there are several key elements that determine the viability of urban wind power, the most important of which are turbine technology, wind resources, costs and regulations (Christopher et al., 2004). Urban environments present a unique set of challenges to wind power, which demand turbine technology specific to these applications because wind directions are affected by the existing buildings.

Since this idea is perceived as new in Malaysia, two experiments are being carried out at the School of Housing, Building \& Planning, Universiti Sains Malaysia. The experiment is still in its infancy. What is promising is that by using an anemometer, the return air was measured to be as $5.0 \mathrm{~m} / \mathrm{s}$ to $6.0 \mathrm{~m} / \mathrm{s}$ and it has been reported that even at $3.0 \mathrm{~m} / \mathrm{s}$, electricity can be generated and so the experiment is being set up to verify this premise. There are two ways to do so, one is from a domestic split unit system where the return air which blows horizontally and the cooling tower unit blows vertically.

\subsection{Compressor}

Compressor is a device that pumps or charges the refrigerant vapor from low pressure to high pressure. It functions as a heart of the air conditioning system. The air velocity of the return air from a compressor depends on its size and branding. Compared to natural wind, return air is predictable as it totally depends on its operating time. A compressor of a laboratory in School of Housing, Building and Planning, USM is used in this experiment.

The air conditioning system normally is switched on during office hours from 8.30 am until $12.30 \mathrm{pm}$ and resumed operation from $2.00 \mathrm{pm}$ until $5.00 \mathrm{pm}$ everyday for five days in a week. Thus a total of seven hours of operating time with a velocity of $5.0 \mathrm{~m} / \mathrm{s}$ is expected to supply some useful energy. With this predictable return air at $5.0 \mathrm{~m} / \mathrm{s}$ means that the return air is not wasted but being converted to provide wind energy for countries which has unreliable natural wind speeds such as Malaysia. A Vertical Axis Wind Turbine (VAWT) is fixed next to the compressor (Figure 4).

As pointed out in above section, which states that the higher the altitude the faster the wind speed, this experiment done at ground level would have no natural wind speed that can be relied upon for energy generation. Therefore using this concept of return air gives the added advantage to the VAWT on both accounts, i.e. on higher altitudes such as up on the flat roof of tall building to capture the faster wind speed and using the predictable return air at ground level.

The hypothesis has identified two variables that need to be adjusted namely,

The existing VAWT propeller fins need to be redesigned 
The distance between the compressor and the blade fins need to be determined.

\subsection{Cooling Tower}

Cooling tower is a bigger variant of the compressor. The hypothesis is the exhaust air produced from it has higher velocities compared to the compressor thus is capable of turning the VAWT to generate electricity more effectively than the latter. Therefore, the exhaust air from cooling tower could be used for bigger scale purposes, for example for commercial buildings such as shopping malls and office buildings.

Cooling tower located between the School of Pharmacy and the Innovation Office of USM was chosen to for this experiment. There are six units of cooling tower located at ground level. At ground level, natural wind cannot be relied upon as the area is blocked by surrounding buildings. The vertical exhaust air from the six units of cooling tower could be harvested by positioning the fins of the VAWT horizontally thus to be redefined as Horizontal Axis Wind Turbine (HAWT). The rest of the components would be similar to the VAWT.

Using an anemometer the average wind velocity of its exhaust is between $6.6-6.8 \mathrm{~m} / \mathrm{s}$. The average of wind velocity which is more than $5.0 \mathrm{~m} / \mathrm{s}$ is sufficient for wind energy harvesting and hypothetically is enough to generate electricity (Gauzin-Muller, 2002).

\section{Conclusion}

In Malaysia, relying on natural wind for the good use of the society has its limitations. One normally depends on it for drying clothes and cool the building interiors as cross ventilation, removing relative humidity (when it comes in as reliable air velocities during night) and removing the radiant heat during the day. But these situations are unpredictable, when it comes, it is appreciated but when it is absent, it is most missed. However, because it is the characteristic of the Malaysian wind, therefore wind power has to be redefined and used from a different angle and that is to use the exhaust wind from man-made mechanical power. The least is to reduce dependence on total conventional electrical power where its exhaust air can be tapped to replenish energy via either a vertical or horizontal air wind turbine. A hybrid system by using both the sun and wind to generate energy to one battery or grid connected would predictably contribute to the amount of renewable energy required to reduce carbon footprint. Sunny days give energy via the solar energy and rainy days which come with wind of a higher velocity would also generate electricity. Exploring the parameters of Malaysian conditions, it is believed that such hypothesis can be proven true. Thus, it helps to reduce urban heat island, and global warming because wind harvesting is pollution-free, clean and an alternative energy that everyone can enjoy.

\section{References}

Abdul Malek, A. R. (1994). Design for Natural Ventilation in Low-Cost Housing in Tropical Climates. University of Wales College of Cardiff, Wales.

Abdul Malek, A. R. (2004). Low Energy Cooling Technology for Malaysian Homes. Penang: Universiti Sains Malaysia Publisher.

Abdul Shukor. (1993). Human Thermal Comfort in Tropical Climates. University College, London.

Ahmed, N. A., Miyatake, Masafumi \& Al-Othman, A.K. . (2009). Hybrid Solar Photovoltaic/ Wind Turbine Energy Generation System with Voltage-based Maximum Power Point Tracking. Electric Power Components and Systems, 37, 43-60.

Azusa, I. (2009). Introducing Natural Ventilation in Selected Malaysian Hotels for Environmental Sustainability. Universiti Sains Malaysia, Penang.

Buttgen, J. (2002). Air-conditioning takes up nearly $70 \%$ of the electricity bill in most hotels In A. M. A. Rahman (Ed.). Penang, Malaysia.

Christopher, D. D. a. M., J.G.J (2004). Wind Power for Urban Applicants. Paper presented at the ASME 2004 Power Conference.

Editor. (2006). Cut air-conditioning usage: Government offices urged to save energy. News Straits Times, p. 12.

Gauzin-Muller, D. (2002). Sustainable Architecture and Urbanism. Basel, Boston: Birkhauser.

Green Building Index: GBI Assessment Criteria for Non-Residential New-Construction (NRIC) (2009).

Ismail, M. R. (2000). An Investigation Into The Choice of Air- Conditioning Design Conditions For Malaysians Offices and The Effect on Energy Consumption in Malaysia. University of Liverpool, Liverpool.

Richards, I. (2001). Hamzah \& Yeang : Ecology of the Sky (The Millennium Series). Australia: Images Publishing Group. 


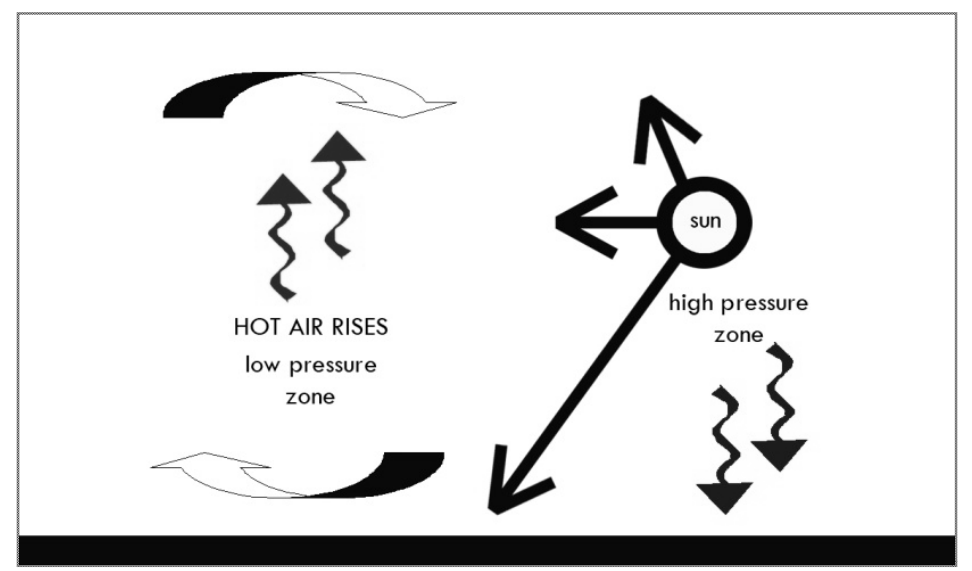

Figure 1. The creation of wind or air movement Description for the above figure.
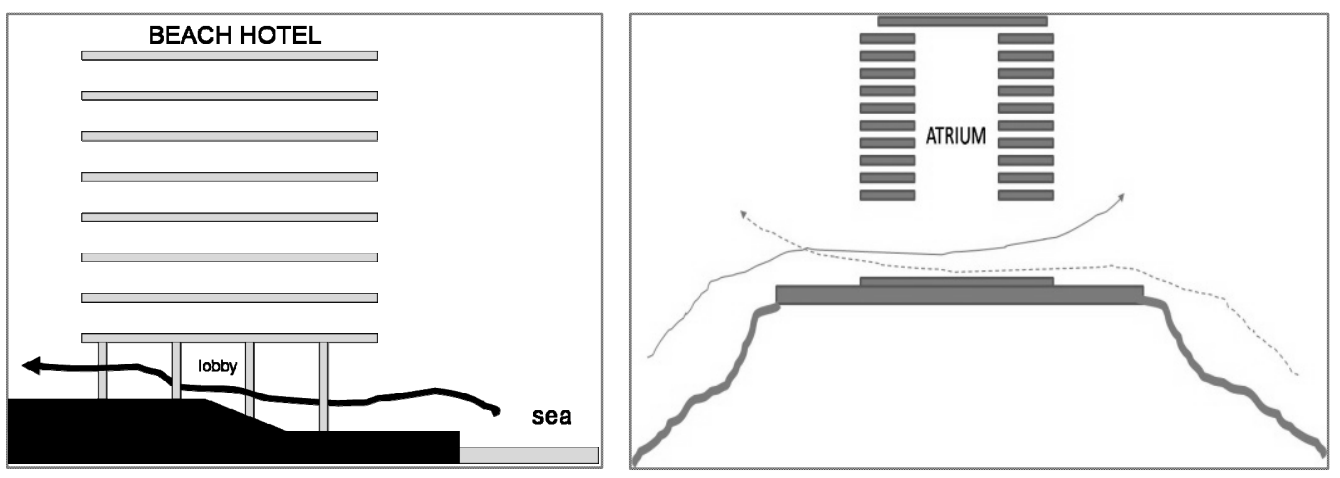

(a)

(b)

Figure 2. (a): Diagrammatic cross section of beach hotel.

(b): Diagrammatic cross section of hotel on hilly area.

Description for the above figure.

Table 1. Comparison of indoor climatic behavior of the two hotel locations

\begin{tabular}{lll}
\hline & $\begin{array}{l}\text { BEACH H OTEL } \\
\text { (Land \& Sea Breeze) }\end{array}$ & $\begin{array}{l}\text { HIL HOTEL } \\
\text { (Prevailing Valley winds) }\end{array}$ \\
\hline SET < Air Temperature & $1^{\circ} \mathrm{C}-1.5^{\circ} \mathrm{C}$ & $1^{\circ} \mathrm{C}-1.5^{\circ} \mathrm{C}$ \\
\hline $\begin{array}{l}\text { Mirror image between } \\
\text { BET and Air Velocity } \\
\text { Air Vel ocity } \rightarrow\end{array}$
\end{tabular}

Description for the above table. 

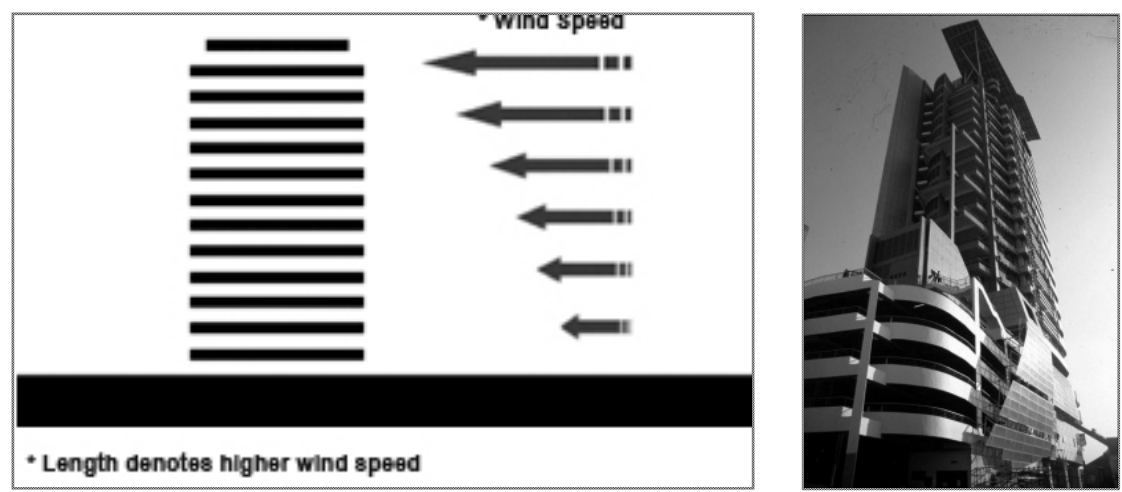

(b)

Figure 3. (a): The principle of altitude and air velocity

(b): The treatment of high rise building façade to accommodate the wind energy (Source: Richards, 2001)

Description for the above figure.

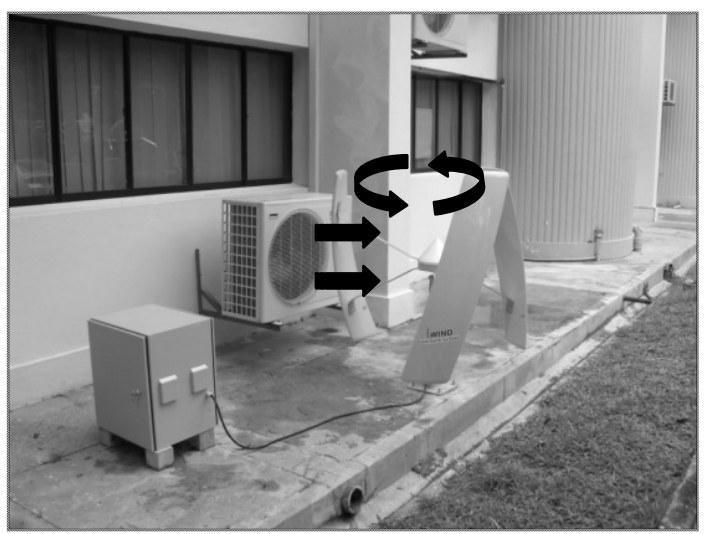

Figure 4. Vertical-axis wind turbine at School of Housing, Building and Planning, USM.

Description for the above figure.
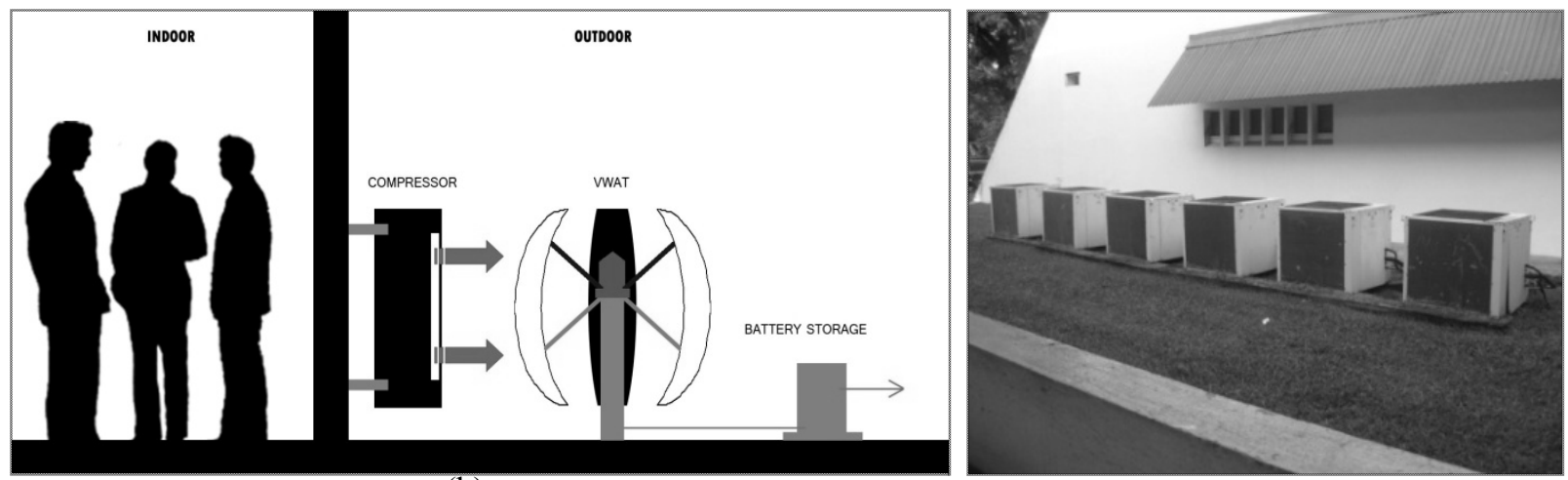

(b)

Figure 5. (a): Generating electricity using natural wind with VAWT on a high rise building. (b): Generating electricity using return air with VAWT at ground level.

Description for the above figure. 


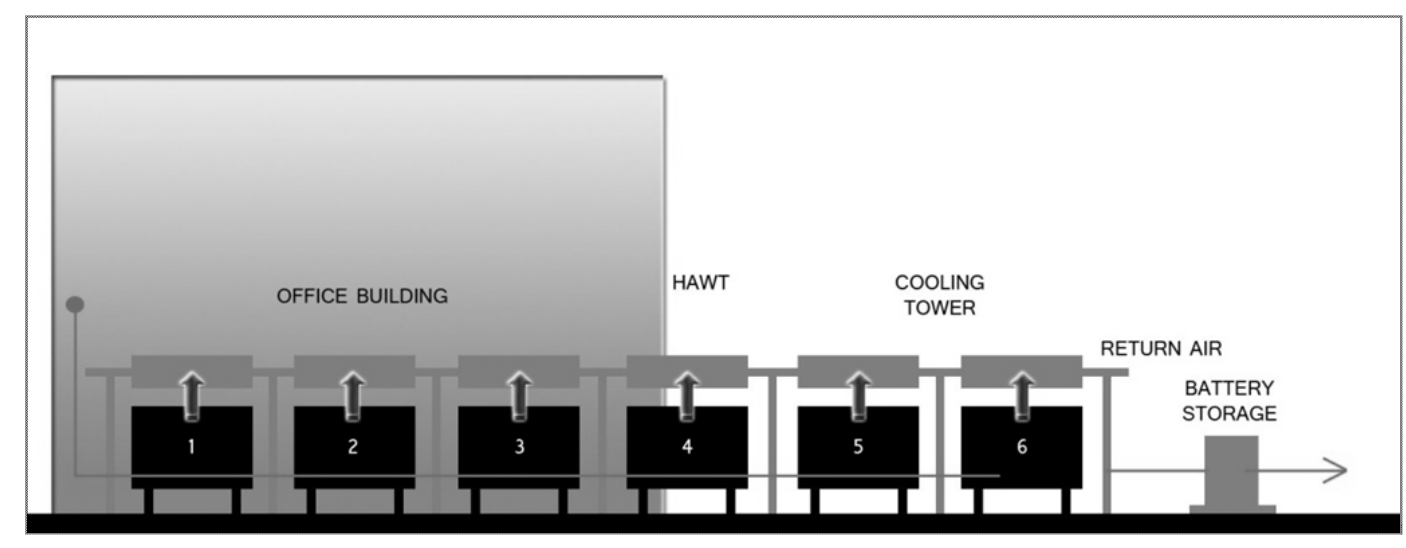

Figure 6. Diagram of six cooling tower connected to an office building Description for the above figure. 